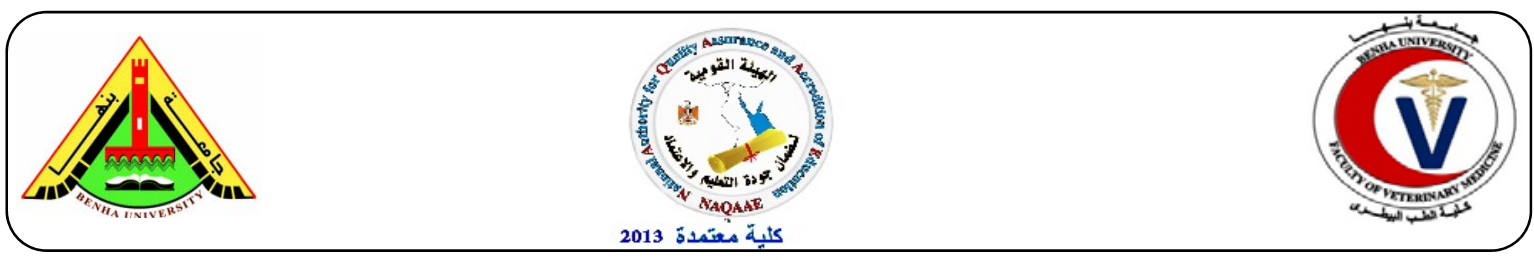

\title{
Biochemical effects of intestinal surgery in gastrointestinal enzyme
}

\author{
Hussein A. Ali ${ }^{1}$, Mohamed K. Mahfouz ${ }^{1}$, Adel M. Sayed ahmed ${ }^{2}$, Badran M. Abd-elwahab ${ }^{1}$ \\ ${ }^{1}$ Department of Biochemistry, Faculty of Veterinary Medicine, Benha University. ${ }^{2}$ Department of \\ Surgery, Faculty of Veterinary Medicine, Benha University
}

\begin{abstract}
A B S T R A C T
This study was performed to investigate the effected of experimental work of intestinal surgery for removal caecum of rabbits on alanine amiotransferase (ALT), aspartate aminotransferase(AST), gamma glutamyletransferase (GGT), alkaline phosphatase (ALP), acid phosphotase (ACP), amylase, lipase, catalase (CAT), ceratine phosphokinase (CPK), lactate dehydrogenase (LDH) and cortisol hormone. Two groups of thirteen healthy female New Zland rabbits were used. The first one contained 15 rabbits and kept as control group. The second contain also 15 rabbits subjected to surgery for removal of caecum of rabbits. Blood sample were collected at 3,6 and 9 days post-operative. The obtained result showed that the increase in serum ALT, AST, GGT, ALP, ACP, amylase, lipase, CAT, CPK, LDH and cortisol hormone were significant increase in experimental group compared with control group. From this result it could be concluded that the biochemical parameter affected with intestinal surgery for removal of rabbit's caecum.
\end{abstract}

Keywords: Rabbits, Caecum, Surgery.

(http://www.bvmj.bu.edu.eg) $\quad$ (BVMJ-30(1): 272-282, 2016)

\section{INTRODUCTION}

$\mathrm{R}$ abbits are herbivores, concentrate selectors and are classified as hindgut (Cecum and colon) fermenters. They have a complicated gastrointestinal anatomy and physiology designed to handle significant amounts of low-energy density fibrous food and to effectively utilize nutrients found in a high fiber diet. In regards to surgery of the GI tract care should be taken when making ventral midline incision, as the cecum and stomach are often directly adjacent to the body wall. Additionally, adhesions can be a common postoperative challenge in rabbits especially associated with gastrointestinal surgery (Alves et al., 2011). The stomach and small intestine in rabbits digest and absorb nutrients very similarly to monogastric animals with hydrochloric acid and pepsin as initiators of digestion. Pancreatic enzyme production, such as amylase, is minimal, with most coming from saliva or bacterial production within the cecotroph. Motilin, a polypeptide hormone secreted by enterochromaffin cells of the duodenum and jejunum, stimulates gastrointestinal smooth muscle. Motilin production is stimulated by fat and inhibited by carbohydrate ingestion. The transit time of the small intestine is rapid compared to other herbivorous species and fiber is quickly moved to the cecum and large intestine. The cecum of rabbits is very large and has a capacity roughly ten times that of the stomach, making up around $40 \%$ of the total gastrointestinal tract. It is a thin-walled organ that folds on itself multiple times and has an internal surface made up of a long spiral fold (sometime referred to as spiral valve) that is continued into the beginning of the colon, an area known as the ampulla coli. The distal tip of the cecum is known as the vermiform appendix (Rea and Patel, 2010). 
In the gastrointestinal tract the immunoinflammatory process is a key component of the mucosal defense against exogenous and endogenous factors. Impairment of this responsem can lead to mucosal injury and to an impairment of the repair process. The inflammatory response is coordinated to a large extent by an array of chemical mediators that are released from the epithelium, immunocytes and nerves within lamina propria. This release occurs in response to injury, infection or exposure of cells to antigens (DeMeo et al., 2002). Inflammatory bowel disease (IBD) is a common name for ulcerative colitis (UC) and Crohn's disease (CD); these are systemic inflammatory diseases of the gastrointestinal (GI) tract. The disease course of IBD is unpredictable; some patients have only a single episode of the active disease and remain in remission for the rest of their lives, other patients have recurrent periods of active disease followed by remission, while still others suffer from a continuously active disease (Beattie 2006).

\subsection{MATERIAL AND METHODS}

\subsection{Experimental Rabbits}

Thirty White male New-Zealand rabbits were divided into two groups (15 mature rabbits of 12-14 weeks old and average body weight ( $2.700-3.200 \mathrm{~kg}$ ) used as control and (15 mature rabbits of 12-14 weeks old and average body weight ( 2.700 $3.200 \mathrm{~kg}$ ) were used in the experimental investigation of this study. Rabbits were obtained from Laboratory Animals Research Center, Faculty of Agriculture, Cairo University.

\subsection{Animal housing and management}

Rabbits were housed in separate metal cages, fresh and clean drinking water was supplied ad-libitum from automatic fountains. Rabbits were kept at constant environmental and nutritional conditions throughout the period of experiment. The animals were kept 15 days for acclimatization before the beginning of the experiment.

\subsection{Ration and additives}

The rabbits were fed on a basal diet throughout the course of the experiment in the form of concentrated diet composed of $40 \%$ barseem hay, $2 \%$ barseem straw, 26 $\%$ Barely, $15 \%$ wheat bran, $13 \%$ soya bean meal, 2.19\% Molasses, $0.25 \% \mathrm{NaCl}, 0.25$ $\%$ Vitamin mineral Mixture, $1 \%$ limestone, $0.13 \%$ Lysine and $0.18 \%$ cysteine and methionine.

\subsection{Preoperative procedure}

Rabbits were fed a normal diet for 15 days. During this period, they were checked in terms of food intake and defecation and a physical examination was performed. At the end of this period, the rabbits were divided into two groups of 15 rabbits as the study and 15 rabbits control groups. The day before the surgery the study groups no food was provided except water to all rabbits for 12 hours before the surgery.

\subsection{Surgical procedure}

All rabbits were anesthetized with the application of Xylazine $\mathrm{HCl}$ (Alfaziyne) $1 \mathrm{~cm}$. IM and then Ketamine HCl (Ketalar, Pfizer, Turkey) $0.5 \mathrm{~cm}$ IM. Following the shaving and disinfection of the abdominal region, laparotomy was performed from the medianline. Acutaneous incision about 2$3 \mathrm{~cm}$-long pieces was removal ceocum of rabbit's .The ends exposed after the resection were reconnected with an end-toend anastomosis technique. The abdominal fascia was closed with $1 / 0$ continuous polyglactine (Polysorb, Tyco) sutures, and the skin was closed by simple interrupt pattern (Abdel-Maksoud, 1996).

\subsection{Postoperative procedure}

Antibiotic administration (40 $\mathrm{mg} / \mathrm{kg}$, ceftriaxone disodium IM), wound care and routine clinical examinations were performed for 5 days after the operation. During this period, rabbits in both the study and control groups were fed a normal diet. At the same time, the rabbits in the study 
group under experimental work each day until the final experiment.

\subsection{Experimental work}

Group I: A healthy control group contains 15 Rabbits without surgery saved as control.

Group II: A surgical group contains 15 Rabbits suspected to surgical removal of cecum.

\subsection{Sampling}

Blood samples were collected after an overnight fasting by vein puncture of the marginal ear vein. Blood samples were collected from all animals of each group (control and experiment groups). The blood samples of surgical group collected for 12 days consequently ever 72 hours intervals. The control and experimental groups were collected in clean sterile tube for serum separation. Serum was separated by centrifugation at 3500 r.p.m for 20 minutes after clotting of the blood for determination serum ALT, AST, GGT, Alkaline phosphatase, Acid phosphatase, Amylase, Lipase, Catalase, CPK, LDH and cortisol hormone. Were determined using the methods described by Ward et al. ( 1993 ), Glick et al., ( 1986 ), Persijn and van der Silk ( 1976), Hillmann and Klin (1971), Tietz and Shuey (1993), Lott and Lu CJ (1991), Johansson and Borg ( 1988 ), Henderson, and Moss (2001), Abbot and Kaplan (1984) and Check et al., ( 1995 ).

\subsection{Statistical analysis}

The obtained data were analyzed and graphically represented using the statistical package for social science (SPSS, 16.0 software, 2009), for obtaining mean and standard error. The data were analyzed using one-way ANOVA to determine the statistical significance of differences among groups. Duncan's test was used for making a multiple comparisons among the groups for testing the inter-grouping homogeneity.

Table1. Effect of intestinal surgery on serum enzymes

\begin{tabular}{lcccc}
\hline Enzymes & Group I & \multicolumn{3}{c}{ Group II (days post surgery) } \\
\cline { 3 - 5 } & & 3 days & 6 days & 9 days \\
\hline \multirow{2}{*}{ ALAT } & 1.060 & $0.7614^{* *}$ & $0.7988^{* *}$ & $1.129^{* *}$ \\
& \pm 17.0 & \pm 42.47 & \pm 54.0 & \pm 65.40 \\
ASAT & 0.5416 & $0.9595^{* *}$ & $1.355^{* *}$ & $0.985^{* *}$ \\
& \pm 23.60 & \pm 55.67 & \pm 70.67 & \pm 87.77 \\
GGT & 0.3634 & 0.5973 & $0.7488^{*}$ & $0.5152^{* *}$ \\
& \pm 38.67 & \pm 12.07 & \pm 20.53 & \pm 27.47 \\
Alkaline phosphatase & 3.342 & $2.436^{* *}$ & $8.482^{* *}$ & $3.770^{* *}$ \\
& \pm 83.47 & \pm 130.8 & \pm 223.9 & \pm 318.3 \\
Acid phosphatase & 0.2082 & $0.362^{* *}$ & $0.4550^{* *}$ & $0.7419^{* *}$ \\
& \pm 3.035 & \pm 7.935 & \pm 13.9 & \pm 21.34 \\
Amylase & 0.7680 & $2.551^{* *}$ & $4.689^{* *}$ & $6.765^{* *}$ \\
& \pm 48.47 & \pm 180.7 & \pm 248.5 & \pm 479.9 \\
Lipase & 0.6817 & $0.7229^{* *}$ & $0.7316^{* *}$ & $1.320^{* *}$ \\
& \pm 32.40 & \pm 65.53 & \pm 74.20 & \pm 87.47 \\
Catalase & 3.101 & $4.268^{* *}$ & $10.57^{* *}$ & $16.99 * *$ \\
& \pm 185.1 & \pm 844.5 & \pm 1456 & \pm 2507 \\
CPK & $6.053 \pm$ & $4.210^{* *}$ & $4.008^{* *}$ & $2.362^{* *}$ \\
& 348.9 & \pm 432.2 & \pm 820.4 & \pm 950.5 \\
LDH & 3.547 & $20.09^{* *}$ & $45.81^{* *}$ & $76.99^{* *}$ \\
& \pm 397.9 & \pm 716.3 & \pm 1571 & \pm 2400 \\
Crtisol & 0.3174 & $0.4473^{* *}$ & $0.4817^{* *}$ & $0.9285^{* *}$ \\
& \pm 5.633 & \pm 11.43 & \pm 18.28 & \pm 24.69 \\
\hline
\end{tabular}




\section{RESULTS}

The results demonstrated in table showed that .The statistical analysis of the mean value in experimental group versus the mean value of the control group revealed that, there was a significant increase in serum ALT, AST, ALP, ACP, amylase, lipase, catalase, CPK, LDH enzyme level and cortisol hormone $(p<0.05)$ at the first three days post-operatively. It was increase high significantly $(\mathrm{P}<0.01)$ at 6 days and very high significant at 9 days at $(\mathrm{P}<0.001)$ post-operatively. The mean value of serum ALT, AST, ALP, ACP, amylase, lipase, catalase, CPK, LDH enzyme level and cortisol hormone level at first 3 days postoperatively showed high significant increase, but in case of GGT The obtained data in table showed that The statistical analysis of the mean value in experimental group versus the mean value of the control group revealed that, there was a very slowly significant increase in serum GGT enzyme level $(p<0.05)$ at 6 days post-operatively. It was slowly increase significantly $(P<$ $0.01)$ at 9 days post-operatively. The mean value of serum GGT level at first 3 days post-operatively showed non- significant increase compare with control group.

\section{DISCUSSION}

The present data in table the mean value of serum GPT increased significant after 3 days postoperative, which became highly significant after 6 days and very high significantly after 9 days postoperative compared with control group this result similar to (Wallace and Chin, 1997).

As regarded the effect of intestinal surgery up on serum GPT, the present data revealed that the serum appeared increase at $(\mathrm{P}<$ $0.01)$ at 3 days and highly increase at $(P<$ $0.001)$ at 6 and 9 days postoperative this result similar to the observation of (Martin and Wallace, 2006).

The recorded resulted increasing in serum GPT level after intestinal surgery for removal caecum of rabbits could be attributed to inflammation of small intestine and intestinal muscular layer, whenever was membrane damaged, GPT would escape and serum concentration would be increased as state by (Cuffari et al., 2005). In addition to the increase serum GPT level after intestinal surgery these were associated with the cell necrosis of hepatic cells, serum GPT were considered highly specific for liver necrosis, as the enzyme level were dramatically increased with hepatocellular destruction this value reported (Pratt and Kaplan 2000). Also it may be related to the increase in GPT because the removal of caecum and blood vessel connection with it leading to intestinal bleeding, and effect on digestion process lead to raised liver enzyme this noticed by (Lukas et al., 2010).

The present data in table the mean value of serum GPT increased significant after 3 days postoperative, which became highly significant after 6 days and very high significantly after 9 days postoperative compared with control group this result similar to (Wallace and Chin, 1997).

As regarded the effect of intestinal surgery up on serum GOT, the present data revealed that the serum appeared increase at $(\mathrm{P}<$ $0.01)$ at 3 days and highly increase at $(P<$ $0.001)$ at 6 and 9 days postoperative this result similar to the observation of (Martin and Wallace, 2006).

The recorded resulted increasing in serum GOT level after intestinal surgery for removal caecum of rabbits could be attributed to inflammation of small intestine and intestinal muscular layer, whenever was membrane damaged, GOT would escape and serum concentration would be increased as state by (Cuffari et al., 2005). In addition to the increase serum GPT level after intestinal surgery these were associated with the cell necrosis of hepatic cells, serum GOT were considered highly specific for liver necrosis, as the enzyme level were dramatically increased with hepatocellular destruction this value reported(Pratt and Kaplan, 2000). Also it may be related to the increase in GOT 
because the removal of ceacum and blood vessel connection with it leading to intestinal bleeding, and effect on digestion process lead to rasid liver enzyme this noticed by (Lukas et al., 2010).

The present data in table the mean value of serum GGT no significant after 3 days postoperative, which became increased gradually significant after 6 days and high significantly after 9 days postoperative compared with control group this result similar to (Wallace and Chin, 1997). As regarded the effect of intestinal surgery up on serum GPT , the present data revealed that the serum appeared decreased at $(P<$ $0.05)$ at 3 days and increase at $(P<0.001)$ at 6 and 9 days postoperative this result similar to the observation of (Martin and Wallace, 2006).

The recorded resulted decrease in serum GGT level after intestinal surgery for removal ceacum of rabbits could be attributed to inflammation of small intestine and intestinal muscular layer, whenever was membrane damaged, GGT would escape and serum concentration would be increased gradually as state by (Cuffari et al., 2005).

In addition to the decrease serum GPT level after intestinal surgery these were associated with the cell necrosis of hepatic cells, serum GGT were considered highly specific for liver necrosis, as the enzyme level were dramatically decreased with hepatocellular destruction this value reported(Nathwani et al., 2005). Also it may be related to the decrease in GGT because the removal of caecum and blood vessel connection with it, and Its removal affected on digestion process leading to nonsignificant at the first experiment this noticed by (Lukas et al., 2010).

The obtained data in table the mean value of serum alkaline phosphatsae increased significant after 3 days postoperative, which became highly significant after 6 days and very high significantly after 9 days postoperative compared with control group this result similar to (Benjamin et al., 1985). As regarded the effect of intestinal surgery up on serum alkaline phosphatsae, the present data revealed that, there was asignificant increase at $(\mathrm{P}<0.01)$ at 3 days. The serum level becomes highly increase at $(P<0.001)$ at 6 and 9 postoperative days. That observation is in accordance with the findings of (Benjamin et al., 1972) those authors demonstrate that the serum alkaline phosphatsae level increase steadily from the onest of acute intestinal surgery.

The observed increasing in serum alkaline phosphatsae level following induction of intestinal surgery for removal ceacum of rabbits could be attributed to the necrosis of the intestinal mucosa and liberation of the enzyme, also inflammation of small intestine. Whenever membrane was damaged, alkaline phosphatsae would escape and serum concentration would be increased as state by (Narisawa et al., 2003). The author explained that the alkaline phosphatase is widly distributed in the body. It is found in high concentration in the osteoblasts, intestinal mucosa, renal tubules liver cells and the placenta. The same author discussed that the elevation of alkaline phosphatase is readily observed in animals with the intestinal episode.

In addition to the increase serum alkaline phosphatsae level after intestinal surgery these were associated with the cell necrosis of hepatic cells, serum alkaline phosphatsae were considered highly specific for liver necrosis, as the enzyme level were dramatically increased with hepatocellular destruction, also it may be related to the increase in alkaline phosphatsae because the removal of caecum and blood vessel connection with it this noticed by (Molnár et al., 2012).

The obtained data in table the mean value of serum acid phosphatsae increased significant after 3 days postoperative, which became highly significant after 6 days and very high significantly after 9 days postoperative compared with control group this result similar to (Wooton and Freeman, 1982).

As regarded the effect of intestinal surgery up on serum acid phosphatsae, the present 
data revealed that, there was asignificant increase at $(P<0.01)$ at 3 days. The serum level becomes highly increase at $(P<0.001)$ at 6 and 9 postoperative days. That observation is in accordance with the findings of (Benjamin et al., 1972) those authors demonstrate that the acid alkaline phosphatsae level increase steadily from the onest of acute intestinal surgery.

The observed increasing in serum acid phosphatsae level following induction of intestinal surgery for removal ceacum of rabbits could be attributed to the necrosis of the intestinal mucosa and liberation of the enzyme, also inflammation of small intestine. Whenever membrane was damaged, acid phosphatsae would escape and serum concentration would be increased as state by (Tuin et al., 2009).

The author explained that the acid phosphatase is widly distributed in the body. It is found in high concentration in the prostate, seminal fluid, RBCs,platelets and the spleen. The same author discussed that the elevation of acid pjoaphatase is readily observed in animals with the intestinal episode. They added that the serum acid phosphatase activity was sensitive and specific for prostate disease, bone disease with an increased osteoclaste activity, hyperthyroidism and splenomegaly.

In addition to the increase serum acid phosphatsae level after intestinal surgery these were associated with the removal of ceacum of rabbits and blood vessel connection with it this noticed by (Riggle et al., 2013).

The present data in table the mean value of serum amylase increased significant after 3 days postoperative, which became highly significant after 6 days and very high significantly after 9 days postoperative for removal ceacum of rabbits compared with control group this result similar to (Vissers et al., 1999).

As regarded the effect of intestinal surgery up on serum amylase, the present data revealed that the serum amylase appeared increase at $(P<0.01)$ at 3 days and highly increase at $(P<0.001)$ at 6 and 9 postoperative days this result similar to the observation of (Pandol et al., 2004).

The recorded resulted increasing in serum amylase level after intestinal surgery for removal ceacum of rabbits could be attributed to inflammation of small intestine and pancreas, whenever amylase would escape and serum concentration would be increased as state by (Kamisawa et al ,2003).

In addition to the increase in the serum concentration of pancreatic enzymes and lipase is commonly an expression of inflammatory or neoplastic pancreatic disease, as the enzyme level were dramatically increased this value reported (Scheele et al., 1987).

Also increased levels of lipase enzymes may be secondary to an imbalance between pancreatic release and renal clearance, but liver damage is also suspected to play a role in inducing pancreatic hyperenzymemia this noticed by (Murakami et al., 2008).

The present data in table the mean value of serum lipase increased significant after 3 days postoperative, which became highly significant after 6 days and very high significantly after 9 days postoperative for removal ceacum of rabbits compared with control group this result similar to (Vissers et al., 1999).

As regarded the effect of intestinal surgery up on serum lipase, the present data revealed that the serum lipase appeared increase at $(\mathrm{P}<0.01)$ at 3 days and highly increase at $(P<0.001)$ at 6 and 9 postoperative days this result similar to the observation of (Pandol, 2004).

The recorded resulted increasing in serum lipase level after intestinal surgery for removal ceacum of rabbits could be attributed to inflammation of small intestine and pancreas, whenever lipase would escape and serum concentration would be increased as state by (Kamisawa et al., 2003).

In addition to the increase in the serum concentration of pancreatic enzymes and lipase is commonly an expression of inflammatory or neoplastic pancreatic 
disease, as the enzyme level were dramatically increased with hepatocellular destruction this value reported (Scheele et al., 1987).

Also increased levels of pancreatic enzymes may be secondary to an imbalance between pancreatic release and renal clearance, but liver damage is also suspected to play a role in inducing pancreatic hyperenzymemia this noticed by (Murakami et al., 2008).

The present data in table the mean value of serum catalase increased significant after 3 days postoperative, which became highly significant after 6 days and very high significantly after 9 days postoperative, compared with control group this result similar to (Nieto et al., 2000).

As regarded the effect of intestinal surgery up on serum catalase, the present data revealed that the serum appeared increase at $(\mathrm{P}<0.01)$ at 3 days and highly increase at $(P<0.001)$ at 6 and 9 days postoperative this result similar to the observation of (Loft and Poulsen, 1999).

The recorded resulted increasing in serum catalase level after intestinal surgery for removal ceacum of rabbits could be attributed to inflammation of small intestine and intestinal muscular layer, increased catalase which are produced through the oxidative burst associated with the inflammatory process in the cell may lead to severe damage to macromolecules, whenever was membrane damaged, catalase would escape and serum concentration would be increased as state by (Head and Jurenka, 2003).

Level of catalase were significantly increased in the present study which was indicative of increased oxidative stress in intestinal surgery as compared to controls, as the enzyme level were dramatically increased with increased oxidative stress this value reported ( Sturniolo et al., 1998).

Also catalase are dominating intracellular antioxidants present or released into the circulation following disease related erythrocyte catastrophe, their serum activities are increased or changed by several orders of magnitude than corresponding erythrocyte this noticed by (Baskol et al., 2008).

The present data in table the mean value of serum CPK increased significant after 3 days postoperative, which became highly significant after 6 days and very high significantly after 9 days postoperative compared with control group this result similar to (Calman et al.,1985).

As regarded the effect of intestinal surgery up on serum $\mathrm{CPK}$, the present data revealed that the serum appeared increase at $(\mathrm{P}<$ $0.01)$ at 3 days and highly increase at $(P<$ $0.001)$ at 6 and 9 days postoperative this result similar to the observation of (Ghanem et al., 1970).

The recorded resulted increasing in serum CPK level after intestinal surgery for removal ceacum of rabbits could be attributed to inflammation of small intestine, intestinal muscular layer and cardiac, whenever was membrane damaged, CPK would escape and serum concentration would be increased as state by (Wasserman et al., 2010).

In addition to the increase serum CPK level after intestinal surgery these were associated with the damaged tissue is a measure of the number of necrotic cells, serum CPK were considered highly specific for cell necrosis, as the enzyme level were dramatically increased with damage of myocardial membrane this value reported(Keshet et al., 2009). Also it may be related to the increase in CPK because the removal of caecum and blood vessel connection with it, and cardiac enzyme a significant increase because surgery this noticed by (Hreinsson et al., 2013).

The present data in table showed that the mean value of serum LDH increased significant after 3 days postoperative, which became highly significant after 6 days and very high significantly after 9 days postoperative for removal caecum of rabbits compared with control group this result similar to (Calman et al., 1985). As regarded the effect of intestinal surgery up on serum $\mathrm{LDH}$, the present data revealed that the serum LDH appeared increase at ( 
$P<0.01)$ at 3 days and highly increase at $(P<0.001)$ at 6 and 9 postoperative days this result similar to the observation of (Ghanem et al.,1970). The recorded resulted increasing in serum LDH level after intestinal surgery for removal caecum of rabbits could be attributed to inflammation of small intestine and cardiac, whenever LDH would escape and serum concentration would be increased as state by (Drent et al., 1996).In addition to the increase in the serum LDH is commonly an expression of inflammatory or cardiac disease, Also increase in LDH level associated with the damaged tissue is a measure of the number of necrotic cells, serum LDH were considered highly specific for cell necrosis, as the enzyme level were dramatically increased with myocardial destruction this value reported (Keshet et al., 2009). Also increased levels of LDH enzyme may be secondary to an imbalance between cardiac release and liver enzyme, but liver damage is also suspected to play a role in inducing cardiac enzyme this noticed by (Hreinsson et al., 2013).

The present data in table the mean value of serum cortisol increased significant after 3 days postoperative, which became highly significant after 6 days and very high significantly after 9 days postoperative, compared with control group this result similar to (Luo et al., 2003). As regarded the effect of intestinal surgery up on serum cortisol, the present data revealed that the serum appeared increase at $(\mathrm{P}<0.01)$ at 3 days and highly increase at $(P<0.001)$ at 6 and 9 days postoperative this result similar to the observation of (Udelsman and Chrousos, 1998). The recorded resulted increasing in serum cortisol level after intestinal surgery for removal caecum of rabbits could be attributed to inflammation of small intestine and the systemic response to surgical injury is complex and involves psychological and physical stress and neuro-endocrine and inflammatory mediators. In humans, there is anticipatory stress that is associated with elevations of cortisol on the day of surgery. Whenever cortisol hormone would escape and serum concentration would be increased as state by (Crema et al., 2005).

In this study, we detected a significant increase in serum cortisol levels postoperatively in the experimental group. This change may be related to a lower incidence of postoperative pulmonary complications in patients undergoing sustained deep inspiration, especially due to cortisol anti-inflammatory role, as the enzyme level were dramatically increased this value reported(Sido et al., 2004). Also it may be related to the increase in cortisol because the removal of caecum and blood vessel connection with it. High levels of cortisol would increase glomerular filtration rate and consequently would result in body's water loss and patients' dehydration this noticed by (Kazama et al., 2005).

\section{CONCULSION}

This study recommended that the presence of caecum of rabbit is very important for this study because help on digestion process.

\section{ACKNOWLEDGMENT}

Special thanks for center of excellence in scientific research (CESR) that follow faculty of veterinary medicine, Benha University, that funded by management supporting excellence (MSE) and Benha University.

\section{REFERENCES}

Abbot, B., Kaplan, A. 1984. Method for the determination of Creatine phosphokinas Clin. Chem Biochem; 1112-116.

Abdel-Maksoud, H. 1996. Biochemical studied on blood of experimentally induced renal failure in rabbits". Ph. D. Thesis, Fac. Vet. Med. (Moshtohor), Zag. Univ.

Alves, J.R. Lopes, L.R., Sasasaki, T. 2001. Perioperative care in an animal model 
for training in abdominal surgery: is it necessary a preoperative fasting? Acta Cir. Bras., 26(6): 541-8.

Baskol, M., Baskol, G., Koçer, D., Ozbakir, O., Yucesoy, M. 2008. Advanced oxidation protein products: a novel marker of oxidative stress in ulcerative colitis. J Clin Gastroenterol; 42: 687-91.

Beattie, R.M., Croft, N.M., Fell, J.M., Afzal, N.A., Heuschkel, R.B. 2006. Inflammatory bowel disease. Arch Dis.; 91: 426-432.

Benjamin, F., Rush, J.R., William, R., Host, M.D., Fewel, J. Jojn, H. 1972. Intestinal ischemia and som organic substance in serum and abdominal fluid " Arch surg., (105): 151-157.

Benjamin, M.M. 1985. Intestinal alkaline phosphatase and sufficient in mesenteric occlusion "J. Surg. Res., (20: 243-246).

Check, J.H., et al, 1995. Falsely elevated steroidal assay levels related to heterophile antibodies against various animal species. Gynecol Obstet Invest 40: 139-140.

Claman, C., Hershey, F., Skaggs, J. 1985. Serum lactate de hydrogenase in the diagnosis of the acute surgical abdomen" surg. 98: 43-51.

Crema, E., Ribeiro, E.N., Hial, A.M., Alves, J.T., Pastore, R., Silva, A.A., 2005. Evaluation of the response of cortisol cortico-trophin after laparoscopic and open chole-cystectomy. Acta Cir Bras 20: 364-370.

Cuffari, C., Dudinsky, M., Darbari, A., Sena, L., Baldassano, R. 2005. Crohn's jejunoileitis: The pediatrician's perspective on diagnosis and management. Inflamm Bowel Dis. ;11: 696-704.

DeMeo, M.T., Mutlu, E.A., Keshavarzian, A., Mark, T., Tobin, M.C., 2002. Intestinal permeation and gastrointestinal Disease. J Clin Gastroenterol 34: 385-396.

Drent, M., Cobben, N.A.M., Henderson, R.F. 1996. Increase of lactate dehydrogenase and its isoenzymes as indicators of lung damage or inflammation. Eur Respir J; 9: 173242.

Ghanem, M., Goodale, R.L., Spanos, P., Tsung, M.S., Wangensteen, O.H. 1970. Value of CPK in recognition of mesenteric infraction of shorter intestinal length: An experimental study. Surg., (68): 635-645.

Glick, M.R., Ryder, K.W., Jackson, S.A. 1986 . Graphical Comparisons of Interferences in Clinical Chemistry Instrumentation. Clin Chem;32: 470474.

Head, K.A., Jurenka, J.S. 2003. Inflammatory bowel disease Part 1. Ulcerative colitis pathophysiology and conventional and alternative treatment options. Altern Med Rev; 8: 247-83.

Henderson, A.R., Moss, D.W. 2001. method for the determination of lactate dehydrogenase Clin Chem Biochem; 352.

Hreinsson, J.P., Gumundsson, S., Kalaitzakis, 2013. Lower gastrointestinal bleeding: incidence, etiology, and outcomes in a population-based setting .Eur J Gastroenterol Hepatol; 25: 37 - 43. Hillmann, G., Klin, Z. 1971. Method for the determination of acid phosphatase J Clin Chem Biochem; 9: 273.

Johansson, L.H., Borg, L.A.H. 1988. Spectrophotometer method for determination of catalase activity in samples Anal.Biochem. 174. 331336.

Kamisawa, T., Matsukawa, M., Amemiya, K.Y., Egawa, N., Okamoto, A., Aizawa, S. 2003. Pancreatitis associated with pancreaticobiliary maljunction. Hepatogastroenterology; 50: $1665-8$.

Kazama, I., Komatsu, Y., Ohiwa, T., Sanayama, K., Nagata, M. 2005. Delayed adrenal sufficiency long after unilateral adrenalectomy: prolonged 
glucocorticoid therapy reduced reserved secretory capacity of cortisol. Int J Urol.; 12: 574-577.

Keshet, R., Boursi, B., Maoz, R. 2009 . Diagnostic and prognostic significance of serum lactate dehydrogenase levels in patients admitted to the department ofmedicine. Am J Med Sci; 337: 24855.

Lott, J.A., L.u., C.J. 1991 . Amylase isoenzymes: assays and application in the diagnosis of acute pancreatitis. Clin Chem; 37: 361-8.

Loft, S., Poulsen, H.E. 1999. Markers of oxidative damage to DNA: 16. Antioxidants and molecular damage. Methods Enzymol; 300: 166-84.

Luo, K., Wang, K.H., Shun, J.M. 2003. Operative stress response and energy metabolism after laparoscopic cholecystectomy compared to open surgery. World J Gastroenterol 9: 847-850.

Lukas, M., Drastich, P., Konecny, M., Gionchetti, P., Urban, O., Cantoni, F., Bortlik, M., Duricova, D., Bulitta, M. 2010. Effect of liver enzymes of patients with moderate to severe ulcerative colitis. Inflamm Bowel Dis; 16: 1180-1186.

Martin, G.R., Wallace, J.L. 2006. Gastrointestinal inflammation: a central component of mucosal defense and repair. Exp Biol Med 231: 130 137. Medilexicon's Medical Dictionary.

Murakami, Y., Uemura, K., Hayasidani, Y., 2008. Asoft pancreatic remnant is association with increased drain fluid pancreatic amylase and serum lipase levels following pancreatoduodenectomy. J Gasterointest surg, 54-6.

Molnár, K., Vannay, A., Szebeni, B., Bánki, N.F., Sziksz, E., Cseh, A., Győrffy, H., Lakatos, P.L., Papp, M., Arató, A., Veres, G. 2012 . Intestinal alkaline phosphatase in the colonic mucosa of children with inflammatory bowel disease. World J Gastroenterol; 18: 3254-3259 [PMID: 22783049 DOI: 10.3748/wjg.v18.i25.3254].

Narisawa, S., Huang, L., Iwasaki, A., Hasegawa, H., Alpers, D.H., Millán, J.L. 2003 . Accelerated fat absorption in intestinal alkaline phosphatase knockout mice. Mol Cell Biol; 23: 7525-7530.

Nathwani, R.A., Kumar, S.R., Reynolds, T.B., Kaplowitz, N. 2005. Marked elevation in serum transaminases: an atypical presentation of choledocholithiasis. Am J Gastroenterol.; 100: 295-298.

Nieto, N., Torres, M.I., Fernández, M.I., Giron, M.D., Ríos, A., Suárez, M.D. 2000 . Experimental ulcerative colitis impairs antioxidant defense system in rat intestine. Dig Dis Sci; 45: 1820-7.

Pandol, S.J. 2004. Neurohumoral control of exocrine pancreatic secretion. Curr Opin Gastroenterol; 20: 435-8.

Persijn, J.P., van der Silk, W.A. 1976. Method for the determination of gamma-glutamyltransferase $\mathrm{J}$ Clin Chem Biochem; 4: 421.

Pratt, D.S., Kaplan, M.M. 2000. Evaluation of abnormal liver-enzyme results in asymptomatic patients. N Engl J Med; 342: 1266-71.

Rea, W.J., Patel, K. 2010. Regulating mechanisms of chemical sensitivity. Reversibility of Chronic Degenerative Disease and Hypersensitivity 1: 337 417.

Riggle, K.M., Rentea, R.M., Welak, S.R., Pritchard, K.A., Oldham, K.T., Gourlay, D.M. 2013. Intestinal alkaline phosphatase prevents the systemic inflammatory response associated with necrotizing enterocolitis. J Surg Res; 180: 21-2.

Sido, B., Teklote, J.R., Hartel, M., Friess, H., Buchler, M.W. 2004. Inflammatory response after abdominal surgery. Best Pract Res Clin Anaesthesiol.; 18(3): 439-54.

Scheele, G., Adler, G., Kern, H. 1987. Exocytosis occurs at the lateral 
plasma membrane of the pancreatic acinar cell during supramaximal secretagogue stimulation. Gastroenterology; 92: 345-53.

Sturniolo, G.C., Mestriner, C., Lecis, P.E., D’Odorico, A., Venturi, C. Irato, P. 1998 . Altered plasma and mucosal concentrations of trace elements and antioxidants in active ulcerative colitis. Scand J Gastroenterol; 33: 644-9.

Tietz, N.W., Shuey, D.F. 1993 . Lipase in serum the elusive enzyme: an overview. Clin. Chem; 39: 746-56.

Tuin, A., Poelstra, K., de Jager-Krikken, A., Bok, L., Raaben, W., Velders, M.P., Dijkstra, G. 2009 . Role of acid phosphatase in colitis in man and rats. Gut; 58: 379-387.

Udelsman, R., Chrousos, G.P. 1998 . Hormonal responses to surgical stress. Adv Exp Med Biol 245: 265-272.
Vissers, R.J., Abu-Laban, R.B., McHugh, D.F. 1999 . Amylase and lipase in the emergency department evaluation of acute pancreatitis. J Emerg Med; 17: 1027-37.

Wallace, J.L., Chin, B.C. 1997 . Inflammatory mediators in gastrointestinal defense and injury. Proc Soc Exp Biol Med 214: 192203.

Ward, M.K., Anderson, S.C., Cockayne, S. 1993 : Enzymology clinical chemistry concept and application ; 238.

Wasserman, A., Shnell, M., Boursi, B. 2010. Prognostic significance of high level of serum certain phosophokinase in patients admitted to the department of medicine. Am J Med Sci; 339: 521.

Wooton, S.F., Freeman, 1982. Separation of canine acid phosphatase by cellulose acetate electrophoresis " Am. J. Vet. Res. 43: 1637 - 164. 